\title{
Correlation between rivaroxaban (Xarelto) plasma activity, patient clinical variables and outcomes in a South African centre
}

\author{
S Louw, ${ }^{1}$ MB BCh, FCPath (SA), MMed (Haem); N P Saragas, ${ }^{2}$ MB BCh, FCS (SA) (Ortho), MMed (Ortho Surg); \\ P N Ferrao, ${ }^{2}$ MB ChB, FCS (SA) (Ortho); T F Chirwa, ${ }^{3}$ MSc, PhD; B F Jacobson, ${ }_{1}^{1}$ MB ChB, MMed (Haem), FRCS (Glasg), FCPath (SA), PhD \\ ${ }^{1}$ Department of Molecular Medicine and Haematology, University of the Witwatersrand, Johannesburg; and National Health Laboratory Service, \\ Johannesburg, South Africa \\ ${ }^{2}$ Netcare Linksfield Orthopaedic Sports and Rehabilitation Centre (Clinic), Department of Orthopaedics, Faculty of Health Sciences, University of \\ the Witwatersrand, Johannesburg, South Africa \\ ${ }^{3}$ Division of Epidemiology and Biostatistics, School of Public Health, Faculty of Health Sciences, University of the Witwatersrand, Johannesburg, \\ South Africa
}

Corresponding author: S Louw (susan.louw@nhls.ac.za)

\begin{abstract}
Background. Low-molecular-weight heparin and vitamin K antagonists such as warfarin are the gold standard for prohylaxis and treatment of venous thromboembolic disease (VTED). Direct oral anticoagulants (DOACs) result in predictable anticoagulation with significantly reduced inter- and intra-patient variability. DOAC absorption is rapid, with a short half-life and relatively few drug interactions. DOACs are effective and safe at fixed doses without activity monitoring. However, specific situations may require assessment of accurate drug activity. Rivaroxaban, a DOAC targeting activated coagulation factor X (FXa), is registered for the prevention and treatment of VTED in South Africa.

Objectives. To establish a prophylactic rivaroxaban activity level range and determine any associations with clinical complications, viz. haemorrhage and/or thrombosis.

Methods. Samples from 115 orthopaedic patients were tested 3 hours after a prophylactic oral dose of 10 mg rivaroxaban with STAGO rivaroxaban anti-FXa reagent on an automated coagulation analyser. Patient demographics and clinical outcomes were documented. Results. The mean rivaroxaban anti-FXa level was $105.7 \mathrm{ng} / \mathrm{mL}$. Two patients developed adverse events on therapy. One patient had minor bleeding (menorrhagia) (drug activity level $288.7 \mathrm{ng} / \mathrm{mL}$ ) and another a deep-vein thrombosis (drug activity level $34.7 \mathrm{ng} / \mathrm{mL}$ ). Statistical analysis demonstrated an association between drug activity and advancing age $(p=0.008)$, most apparent among those aged $\geq 65$ years. Conclusions. Measuring rivaroxaban activity levels may reduce uncertainty if treatment failure and complications occur. Patients aged $\geq 65$ years should be closely monitored. A local expected rivaroxaban activity level for patients on rivaroxaban prophylaxis has been established.

S Afr Med J 2016;106(10):1017-1020. DOI:10.7196/SAMJ.2016.v106i10.10584
\end{abstract}

Heparin and warfarin, a vitamin $\mathrm{K}$ antagonist, were first widely used to treat venous thromboembolic disease (VTED) in the early 1940s. ${ }^{[1]}$ Later low-molecular-weight heparin followed by a vitamin $\mathrm{K}$ antagonist became the recommended therapeutic regimen. ${ }^{[2]}$ Vitamin K antagonists have also been the drugs of choice in preventing thromboembolic events in patients with atrial fibrillation. The major problem with warfarin has been unpredictable pharmacodynamic and pharmacokinetic properties, including food and drug interactions, with resultant marked fluctuation in anticoagulation control in a significant number of patients. This, together with the large number of patients on long-term oral anticoagulation, has been the impetus for the development of oral alternatives by pharmaceutical companies. ${ }^{[3,4]}$

Direct oral anticoagulants (DOACs) target individual activated coagulation factors, and their pharmacological properties are detailed in Table 1. These agents have been investigated in multicentre trials to establish efficacy and safety in the treatment and prevention of venous thromboembolism in many clinical conditions (Tables 2 and 3). The two agents registered in South Africa (SA) to date are rivaroxaban (Xarelto; Bayer), a direct factor Xa (FXa) inhibitor, and dabigatran (Pradaxa; Boehringer Ingelheim), a factor IIa (thrombin) inhibitor. Both these agents are currently registered in SA for the treatment and prevention of VTED, i.e. deep-vein thrombosis (DVT) and pulmonary embolism (PE), as well as for prevention of stroke and systemic embolism in patients with non-valvular atrial fibrillation.
Because up to $80 \%$ of the active component of dabigatran is excreted renally, any renal impairment, especially in the elderly, can result in toxicity with resultant haemorrhage. Although the rate and severity of major haemorrhage were lower in trial patients on rivaroxaban than in those on standard therapy, overall haemorrhagic complications occurred with the same frequency. ${ }^{[4]}$

Studies have demonstrated DOACs to be effective and safe at fixed doses without laboratory activity monitoring. Evidence has shown that qualitative drug activity information seems to be adequate in most clinical situations. There are, however, specific situations where assessment of accurate drug activity levels may be required (Table 4) ${ }^{[5,6]}$

The lack of requirement for routine monitoring of DOACs is based on the assumed similarity in pharmacokinetic and pharmacodynamic responses between individuals with varying demographics, including age, race, gender, renal function and body mass index (BMI). It has, however, been estimated that the same dose of a DOAC can produce an up to $30 \%$ difference in thrombin generation inhibition. ${ }^{[7]}$ There has been speculation that bleeding would be more likely in high responders and thrombosis more likely in low responders. Clinical trials usually exclude patients with impaired renal function, extremes of age (i.e. $<18$ and $>65$ years), those with an increased bleeding risk and those at the extremes of body weight. The lack of a need to monitor that was demonstrated in the trials may therefore not be applicable in real-life situations. 
Table 1. Overview of DOACs registered in $\mathrm{SA}^{[3]}$

\begin{tabular}{|c|c|c|}
\hline & Rivaroxaban & Dabigatran \\
\hline Mechanism of action & Direct FXa inhibitor & Direct thrombin inhibitor \\
\hline Route of administration & Oral & Oral (prodrug) \\
\hline Fixed-dose administration & Yes & Yes \\
\hline Onset of action & Rapid (within 2 hours) & Rapid (within 2 hours) \\
\hline Pharmacokinetics: bioavailability after oral administration & $60-86 \%$ & $\sim 6 \%$ \\
\hline Half-life & $7-11$ hours & $14-17$ hours \\
\hline Excretion & $\begin{array}{l}\text { Biliary/faecal ( } 28 \%) \text {; renal ( } 33 \% \text { metabolised, } \\
33 \% \text { excreted unchanged) }\end{array}$ & Renal (80\%) \\
\hline Anticoagulant response & Predictable & Predictable \\
\hline Routine coagulation monitoring needed & No & No \\
\hline Food interactions & Absorption moderately increased by food & Delayed absorption with food \\
\hline Drug interactions & $\begin{array}{l}\text { Ketoconazole, itraconazole, voriconazole, } \\
\text { posaconazole, fluconazole, ritonavir, } \\
\text { phenytoin, carbamazepine, phenobarbital, } \\
\text { aspirin, NSAIDs, St John's wort, rifampicin }\end{array}$ & $\begin{array}{l}\text { NSAIDs, St John's wort, rifampicin, } \\
\text { verapamil, clarithromycin, } \\
\text { amiodarone, verapamil, aspirin (with } \\
\text { higher doses of dabigatran) }\end{array}$ \\
\hline Risk of thrombocytopenia & Minimal & Minimal \\
\hline
\end{tabular}

Table 2. High-level summary rivaroxaban clinical trials

\begin{tabular}{|c|c|c|c|}
\hline Clinical indication & Trial name, year, $n$ & Treatments & $\begin{array}{l}\text { Trial design, number of } \\
\text { participating countries }\end{array}$ \\
\hline $\begin{array}{l}\text { VTED prophylaxis } \\
\text { in total hip and knee } \\
\text { arthroplasty }\end{array}$ & $\begin{array}{l}\text { RECORD } 1-3,2008 \text {, } \\
n=4772 \text { v. } 4809\end{array}$ & $\begin{array}{l}\text { Rivaroxaban } 10 \mathrm{mg} \\
\text { orally v. enoxaparin } \\
40 \mathrm{mg} \text { subcutaneously } \\
\text { once daily }\end{array}$ & $\begin{array}{l}\text { Parallel groups, double } \\
\text { blind, } 27 \text { countries }\end{array}$ \\
\hline $\begin{array}{l}\text { VTED treatment: } \\
\text { DVT and PE }\end{array}$ & $\begin{array}{l}\text { Einstein-DVT and } \\
\text { PE, } 2010 / 2012 \text {, } \\
n=4150 \text { v. } 4131\end{array}$ & $\begin{array}{l}\text { Rivaroxaban } 15 \mathrm{mg} \text { twice } \\
\text { daily for } 3 \text { weeks, then } \\
20 \mathrm{mg} \text { daily v. standard } \\
\text { therapy (enoxaparin } \\
\text { followed by warfarin) }\end{array}$ & $\begin{array}{l}\text { Parallel groups, open } \\
\text { label, } 38 \text { countries }\end{array}$ \\
\hline SPAF & $\begin{array}{l}\text { ROCKET-AF, } 2010 \text {, } \\
n=7131 \text { v. } 7133\end{array}$ & $\begin{array}{l}\text { Rivaroxaban } 20 \mathrm{mg} \\
\text { daily v. warfarin }\end{array}$ & $\begin{array}{l}\text { Parallel groups, double } \\
\text { blind, } 45 \text { countries }\end{array}$ \\
\hline
\end{tabular}

\section{Table 3. High-level summary dabigatran clinical trials}

\begin{tabular}{|c|c|c|c|}
\hline Clinical indication & Trial name, year, $n$ & Treatments & $\begin{array}{l}\text { Trial design, number } \\
\text { of participating } \\
\text { countries }\end{array}$ \\
\hline $\begin{array}{l}\text { VTED prophylaxis } \\
\text { in total hip } \\
\text { arthroplasty }\end{array}$ & $\begin{array}{l}\text { RE-NOVATE, } 2007 \text {, } \\
n=2184 \text { v. } 2165\end{array}$ & $\begin{array}{l}\text { Dabigatran } 150 \text { or } \\
220 \mathrm{mg} / \mathrm{d} \mathrm{v} \text {. } \\
\text { enoxaparin } 40 \mathrm{mg} / \mathrm{d}\end{array}$ & $\begin{array}{l}\text { Parallel groups, } \\
\text { double blind, } \\
\text { multiple countries }\end{array}$ \\
\hline $\begin{array}{l}\text { VTED treatment: } \\
\text { DVT and PE }\end{array}$ & $\begin{array}{l}\text { RE-COVER, 2009/2011, } \\
n=2568 \text { v. } 2560\end{array}$ & $\begin{array}{l}\text { Dabigatran } 150 \mathrm{mg} \\
\text { twice daily v. } \\
\text { warfarin }\end{array}$ & $\begin{array}{l}\text { Parallel groups, } \\
\text { double blind, } \\
31 \text { countries }\end{array}$ \\
\hline SPAF & $\begin{array}{l}\text { RE-LY, } 2010 \text {, } \\
n=12257 \text { v. } 12114\end{array}$ & $\begin{array}{l}\text { Dabigatran } 110 \\
\text { or } 150 \text { mg daily v. } \\
\text { warfarin }\end{array}$ & $\begin{array}{l}\text { Parallel groups, } \\
\text { open with blinded } \\
\text { assessment, } \\
44 \text { countries }\end{array}$ \\
\hline
\end{tabular}

A study by Reilly et al. ${ }^{[8]}$ on the effect of dabigatran plasma concentrations showed that laboratory measurement of drug activity is important and suggests that testing will become more widespread in the future as doctors strive to reduce complications and improve efficacy. This study concluded that both ischaemic stroke and bleeding outcomes correlated with dabigatran plasma concentrations. It is therefore important for clinical laboratories to have the ability to measure drug activity rapidly.

Rivaroxaban exerts a direct anti-FXa activity in plasma. The rational choice to measure direct FXa-inhibitors is therefore an anti-FXa assay. A number of studies have concluded that anti-FXa chromogenic assays are more specific and sensitive than routine clotting test-based assays. In addition, there is a better correlation between plasma concentrations measured by liquid chromatography/mass spectrometry and levels estimated by antiFXa assays than those obtained using the routine prothrombin time (PT) assay. The rivaroxaban anti-FXa assay demonstrates an adequate linearity response to increasing concentrations of rivaroxaban. ${ }^{[9,10]}$ Commercial reagents are available for measuring rivaroxaban anti-FXa activity on routine automated coagulation analysers. It is essential for every laboratory to establish its own reference range in its patient-specific population and laboratory environment. ${ }^{[5,8]}$

\section{Objectives}

To establish an expected rivaroxaban activity level for patients on prophylactic doses of 
Table 4. Clinical situations in which the measurement of DOAC anticoagulant activity is potentially useful

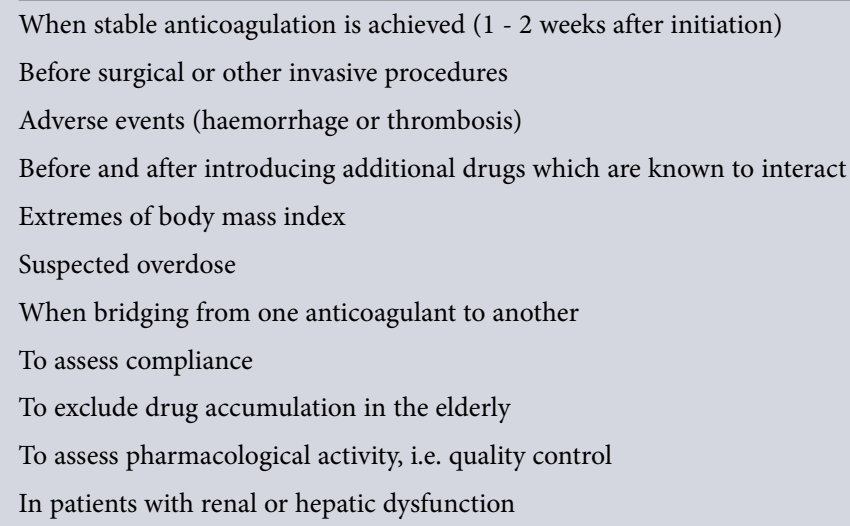

Table 5. Demographic and clinical characteristics of the patients $(N=115)$

\begin{tabular}{ll}
\hline Factor & $\boldsymbol{n}(\%)$ \\
\hline Gender & \\
$\quad$ Male & $59(51.3)$ \\
$\quad$ Female & $56(48.7)$ \\
Age (yr) & \\
$<65$ & $89(77.4)$ \\
$\quad \geq 65$ & $26(22.6)$ \\
BMI & \\
Underweight & $1(0.9)$ \\
Normal & $15(13.0)$ \\
Overweight & $43(37.4)$ \\
Obese & $56(48.7)$ \\
eGFR (mL/min) & \\
$<60$ & $9(7.8)$ \\
$\geq 60$ & $106(92.2)$ \\
Anti-FXa (ng/mL), mean (SD) & 105.7 \\
& $(58.61)$
\end{tabular}

rivaroxaban as well as to assess any association between clinical complications, viz. haemorrhage and/or thrombosis, and drug levels.

\section{Methods}

This was a cross-sectional pilot study measuring rivaroxaban anti-FXa activity in orthopaedic patients admitted to a private hospital in Gauteng Province, SA, for elective foot and ankle surgery. The study was conducted over a 9-month period between 2014 and 2015. Ethics approval was obtained from the Human Research Ethics Committee (Medical) of the University of the Witwatersrand, Johannesburg, and unconditional approval was given (ref. no. M131165).

\begin{tabular}{|c|c|c|}
\hline Factor & $\begin{array}{l}\text { Anti-FXa (ng/ } \\
\text { mL), mean (SD) }\end{array}$ & $p$-value \\
\hline \multicolumn{3}{|l|}{ Gender } \\
\hline Male & $100.54(51.35)$ & \\
\hline Female & $111.83(65.32)$ & 0.283 \\
\hline \multicolumn{3}{|l|}{ Age group (yr) } \\
\hline$<65$ & $98.09(55.09)$ & \\
\hline$\geq 65$ & $132.14(63.61)$ & 0.009 \\
\hline \multicolumn{3}{|l|}{ BMI } \\
\hline Normal & $83.54(50.01)$ & \\
\hline Overweight & $118.72(59.80)$ & \\
\hline Obese & $100.62(58.12)$ & 0.095 \\
\hline \multicolumn{3}{|l|}{ eGFR (mL/min) } \\
\hline$<60$ & $136.64(52.14)$ & \\
\hline$\geq 60$ & $103.17(58.60)$ & 0.100 \\
\hline
\end{tabular}

Venous blood was collected from 115 consecutive orthopaedic patients post surgery, 3 hours after administration of a prophylactic oral dose of $10 \mathrm{mg}$ rivaroxaban. Patient demographics (age, race, gender, BMI and estimated glomerular filtration rate (eGFR)) as well as clinical outcomes were documented. Blood samples were analysed with STAGO rivaroxaban anti-FXa reagent on an automated coagulation analyser after successful calibration and performance of controls. Drug activity was measured as antiFXa activity in $\mathrm{ng} / \mathrm{mL}$.

\section{Statistical analysis}

A descriptive analysis was conducted which included summary measures, i.e. mean and standard deviation (SD) for continuous variables such as age, BMI and eGFR. We also presented the mean (SD) for anti-FXa as an outcome variable. Frequency tabulations were also presented for categorical variables: gender, age group ( $<65$ years and $\geq 65$ years) and BMI (categorised into underweight, normal, overweight and obese).

An investigation of statistical associations between the outcome variable and demographic factors was performed using a $t$-test for comparing two groups and analysis of variance (ANOVA) where more than two groups were being compared. The tests were conducted at a $5 \%$ significance level. Further, a linear regression analysis was conducted through a univariate regression model. Factors found significant at a $20 \%$ level in the univariate analysis were then considered in the multiple linear regression analysis.

\section{Results}

A total of 115 patients, of whom 56 (48.7\%) were female, were included (Table 5). The mean age was 54 years (SD 15), with 89 patients (77.4\%) being $<65$ years of age. Ninety-nine patients $(86.1 \%)$ were overweight $(\mathrm{BMI}>25)$, with $56(56.6 \%)$ classified as obese.

The mean rivaroxaban anti-FXa level in the study population 3 hours after receiving a $10 \mathrm{mg}$ dose was $105.7 \mathrm{ng} / \mathrm{mL}$ (95\% confidence interval (CI) 94.9 - 116.6).

Two patients experienced adverse events on rivaroxaban therapy. A 43-year-old woman with normal renal function and an elevated BMI of 40 had minor bleeding (menorrhagia) without a decrease in haemoglobin. Her rivaroxaban level was $288.7 \mathrm{ng} / \mathrm{mL}$. The second adverse event occurred in a 47-year-old man who developed a below-knee DVT. He had a normal BMI of 22 , with a rivaroxaban activity level of $34.7 \mathrm{ng} / \mathrm{mL}$.

After considering significant factors at univariate level, the final multiple linear regression model demonstrated a statistically significant association between drug activity and advancing age $(p=0.008)$, this being most apparent among patients aged $\geq 65$ years. Creatinine clearance as estimated by the eGFR, however, did not demonstrate a statistically significant association with drug level $(p=0.100)$. There was no association between drug level and the other demographic variables, such as gender $(p=0.283)$ and BMI $(p=0.095)$ (Table 6).

\section{Conclusions}

Commercial assays are available to measure rivaroxaban anti-FXa activity. The clinical application of rivaroxaban activity levels may reduce uncertainty in the event of treatment failure and bleeding complications. The mean rivaroxaban anti-FXa level in the study population 3 hours after receiving 
a $10 \mathrm{mg}$ dose was $105.7 \mathrm{ng} / \mathrm{mL}$, with a range of 25.0 - 283.2. This preliminary pilot study demonstrated a statistically significant association between advanced age and rivaroxaban activity levels, but no association with eGFR. Estimated creatinine clearance reflected by the eGFR is, however, not sensitive enough to detect deterioration in renal function, especially with advancing age ${ }^{[11]}$ Not only are elderly patients at an increased risk of venous thromboembolism, but they are also at an increased risk of bleeding. Increase bleeding risk in the elderly is related to comorbid diseases such as hypertension and malignancy, deteriorating renal function, polypharmacy and frailty with an increased risk of falls. ${ }^{[12,13]}$ Although the significance of the increased rivaroxaban activity levels in the elderly is unknown, this study suggests that patients aged $\geq 65$ years on therapy should be closely monitored. A local expected rivaroxaban activity level for patients on prophylactic therapy has been established.

\footnotetext{
1. Barritt DW, Jordan SC. Anticoagulant drugs in the treatment of pulmonary embolism: A controlled trial. Lancet 1960;1(7138):1309-1312.

2. Bikdeli B, Sharif-Kashani B. Prophylaxis for venous thromboembolism: A great global divide between expert guidelines and clinical practice? Semin Thromb Hemost 2012;38(2):144-155. DOI: $10.1055 / s-0032-1301412$
}

3. Tripodi A, Di Iorio G, Lippi G, Testa S, Manotti C. Position paper on laboratory testing for patients aking new oral anticoagulants: Consensus document of FCSA, SIMeL, SIBioC and CISMEL. Clin aking new oral anticoagulants: Consensus document of FCSA, SIM

4. Borris LC. Emerging antithrombotic agents for thromboprophylaxis, clinical potential and patient considerations. J Blood Med 2010;1:123-130. DOI:10.2147/JBM.S6543

5. Tripodi A. The laboratory and the direct oral anticoagulants. Blood 2013;121(20):4032-4035. DOI:10.1182/blood-2012-12-453076

6. Molenaar PJ, Dinkelaar J, Leyte A. Measuring rivaroxaban in a clinical laboratory setting, using common coagulation assays, Xa inhibition and thrombin generation. Clin Chem Lab Med 2012;50(10):1799-1807. DOI:10.1515/cclm-2012-0055

7. Al Dieri R, Hemker HC. Monitoring new oral antithrombotics: What we should know before we can decide. J Thromb Haemost 2010;8(12):2833-2835. DOI:10.1111/j.1538-7836.2010.04057

8. Reilly PA, Lehr T, Haertter S, et al., on behalf of the RE-LY investigators. The effect of dabigatran plasma concentrations and patient characteristics on the frequency of ischemic stroke and major bleeding in atrial fibrillation patients. J Am Coll Cardiol 2014;63(4):321-328. DOI:10.1016/j.jacc.2013.07.104 in atrial fibrillation patients.) Am Coll Cardiol 2014;63(4):321-328. DOI.10.11616).jacc.2013.07.104 Kitchen S, Gray E, Mackie I, Baglin T, Makris M, BCSH Committee. Measurement of non-coumarin anticoagulants and their effects on tests of haemostasis: Guidance from the British C
Standards in Haematology. Br J Haematol 2014;166(6):830-841. DOI:10.1111/bih.12975

10. Harenberg J, Du S, Krämer S, et al. Novel methods for assessing oral direct factor Xa and thrombin inhibitors: Use of point-of-care testing and urine samples. Semin Thromb Hemost 2013;39(1):66-71.
inter inhibitors: Use of point-of-care testing and urine samples. Semin Thromb Hemost 2013;39(1):66-71.

DOI:10.1055/s-0032-1331155

1. Lopez-Giacoman S, Madero M. Biomarkers in chronic kidney disease, from kidney function to kidney damage. World J Nephrol 2015;4(1):57-73. DOI:10.5527/wjn.v4.i1.57

12. Tulner LR, Kuper IM, van Campen JP, et al. Contraindications for anticoagulation in older patients with atrial fibrillation: A narrative review. Curr Drug Saf 2010;5(3):223-233. DOI:10.2174/157488610791698253

13. Lacut K, Le Gal G, Mottier D. Primary prevention of venous thromboembolism in elderly medical patients. Clin Interv Aging 2008;3(3):399-411.

Accepted 8 April 2016 